\title{
The evaluation of children with cerebral palsy admitted to the pediatric neurology outpatient department
}

\author{
(D) Handan HAKYEMEZ TOPTAN \\ (D) Sabiha PAKTUNA KESKIN \\ Department of Pediatric Neurology, \\ İstanbul University-Cerrahpasa, \\ Cerahpaşa Faculty of Medicine, \\ İstanbul, Turkey
}

\section{ORCID ID}

HHT : 0000-0002-6966-8514

SPK : 0000-0002-5109-5308

\begin{abstract}
Objective: Cerebral palsy (CP) is a neurological condition that occurs as a result of non-progressive damage in the immature brain and is characterized by impairment of muscle tone and posture. This study aims to evaluate the risk factors and imaging findings of patients with $\mathrm{CP}$.

Material and Methods: Medical records of patients with CP at the Pediatric Neurology Clinic of Cerrahpasa Medical School were evaluated retrospectively. Demographic and clinical characteristics were collected from medical records: Gestational age, birth weight, intrauterine growth retardation (IUGR), delivery mode, type of CP, risk factors, accompanying diseases, computed tomography (CT), magnetic resonance imaging $(\mathrm{MRI})$, and electroencephalography findings were recorded.
\end{abstract}

Results: A total of 169 patients were enrolled in the study. The mean age at diagnosis was $27.3 \pm 26.1$ months. One hundred eight $(66.2 \%)$ patients were term and $55(33.7 \%)$ were preterm. The delivery mode was vaginal in 99 (58.6\%) cases and cesarean section in $70(40.4 \%)$ cases. Ninety-six cases $(56.8 \%)$ were male and 73 $(43.2 \%)$ were female. Birth weights were $<2500 \mathrm{~g}$ in 59 cases $(34.9 \%)$ and $2500-4500$ $g$ in 110 cases $(65 \%)$. The types of CP were spastic $(n=144,86 \%)$, dyskinetic $(n=13$, $7.7 \%)$, mixed ( $n=6,3.6 \%)$ and ataxic-hypotonic type $(n=5,3 \%)$. In subgroup analysis, $65(38.5 \%)$ cases were quadriparetic, 43 (25.6\%) cases were diplegic, 35 (20.7\%) cases were hemiparetic, and $2(1.2 \%)$ cases were monoparetic. The reasons for CP were asphyxia $(n=99,58.9 \%)$, low birth weight $(n=61,36.1 \%)$, prematurity $(n=55$, $32.5 \%)$, hyperbilirubinemia $(n=16,9.5 \%)$, meningitis $(n=7,4.1 \%)$, intracranial vascular processes $(n=7,4.2 \%)$, sepsis $(n=6,3.6 \%)$, hydrocephalus $(n=5,3 \%)$, genetic anomalies $(n=5,3 \%)$, and hypoglycemia $(n=1,0.6 \%)$. No risk factors could be determined in eight (4.7\%) cases. Imaging techniques (CT and/or MRI) showed encephalomalacia, which was considered as the main finding of hypoxic-ischemic encephalopathy, in 45 (26.6\%) cases. Imaging results of 15 (8.9\%) patients were normal.

Conclusion: This study results showed that asphyxia, low birth weight, and prematurity are the main reasons for the development of $\mathrm{CP}$. Encephalomalacia is the most common imaging finding, but imaging may be also normal in some patients with CP.

Keywords: Cerebral palsy, newborn, spasticity.

Cite this article as: Hakyemez Toptan $\mathrm{H}$, Paktuna Keskin S. The evaluation of children with cerebral palsy admitted to the pediatric neurology outpatient department. Zeynep Kamil Med J 2021;52(1):32-37.

Received: December 03, 2020 Accepted: February 16, 2021 Online: March 29, 2021

Correspondence: Handan HAKYEMEZ TOPTAN, MD. İstanbul Üniversitesi-Cerrahpaşa, Cerahpaşa Tıp Fakültesi, Çocuk Nörolojisi Anabilim Dalı, İstanbul, Turkey.

Tel: +90 4143177 e-mail: hhandan98@hotmail.com

๑) Copyright 2021 by Zeynep Kamil Medical Journal - Available online at www.zeynepkamilmedj.com 


\section{INTRODUCTION}

Cerebral palsy (CP) is a postural and movement disorder that develops as a result of injury in the developing brain before, during or after birth, which may progress with permanent motor dysfunction. Prematurity, vascular, inflammatory, and traumatic causes play a role in its etiology. ${ }^{[1]}$ In CP, motor retardation is often accompanied by sensory (seeing, hearing, etc.), cognitive (attention, memory, learning, interpretation, execution, etc.), communication (language, communication with body language, etc.), and behavioral (hyperactivity, impulsivity, aggression, etc.) dysfunctions, epilepsy, and secondary musculoskeletal system problems. ${ }^{[2]}$ In parallel with technological advancements, new approaches are emerging in treatment and rehabilitation techniques in CP. Etiological distribution of CP, life expectancy and increased quality of life are accepted as criteria determining the development level of societies. ${ }^{[3]}$ In this study, we aimed to evaluate the etiology, clinical course, and laboratory findings of patients with CP.

\section{MATERIAL AND METHODS}

The study was designed as a retrospective cross-sectional study. The study protocol was approved by the Cerrahpasa University Medical Faculty Ethics Committee. Files of the pediatric patients followedup in the Pediatric Neurology Outpatient Clinic of the Cerrahpasa University Medical Faculty, Department of Pediatrics with the diagnosis of CP between October 01, 2003 and October 01, 2009 were retrospectively reviewed. Patients' gender, diagnosis, age at admission, delivery mode, birth weight, type of $\mathrm{CP}$, risk factors, accompanying diseases, imaging, and electroencephalography (EEG) findings were recorded. Types of CP were grouped as spastic, dyskinetic, ataxic/ hypotonic, and mixed type. Spastic types were further classified as quadriparesis, diplegic, hemiparesis, and monoparesis CP. Since most of the cases presented with a previous diagnosis, we considered the age at the time of admission to our outpatient clinic instead of the age at diagnosis as a criterion. We grouped ages at admission as $<6$ months, 6-12 months, 12-24 months, and >24 months.

Conditions known as risk factors in the etiology of CP such as gestational age, birth weight, delivery mode and intrauterine retardation, consanguineous marriage, genetic stigmata, and congenital metabolism disorders were taken into account. Gestational age, birth weight, delivery mode, and conditions that may cause intrauterine growth retardation, which are known as risk factors in the etiology of $\mathrm{CP}$, were determined as follows: Delivery mode was separately evaluated as delivery at home or hospital, normal spontaneous vaginal delivery (NSVD), and cesarean section (C/S). Birth weight was classified as $<2500 \mathrm{~g}, 2500-4500 \mathrm{~g}$, and $<4500 \mathrm{~g}$. Gestational age was evaluated as term and preterm ( $\leq 37$ hafta). As the risk factors; asphyxia, low-birth weight, prematurity, meningitis, sepsis hyperbilirubinemia, hydrocephalus, genetic anomalies, and vascular processes such as intracranial hemorrhage and thrombosis, acute metabolic events such as hypoglycemia and consanguineous marriage were examined separately.

Patients whose seizures were clinically supported by EEG findings were considered to have epilepsy. Patients with EEG findings, but who had no clinical seizures were accepted to have EEG anomaly. Presence of epilepsy, which is characterized by the tendency of the brain to produce continuous epileptic seizures and associated epileptiform abnormalities in EEG were recorded. Imaging findings were examined as auxiliary data in distinguishing CP subgroups and associated conditions. Accompanying diseases were determined. Types of $\mathrm{CP}$, risk factors, and laboratory findings were matched and compared.

Statistical analysis was performed using SPSS 16.0. Ordinal variables were expressed as median and interquartile range. Categorical data were given as frequency and percentage Descriptive statistics were expressed as mean \pm standard deviation. Chi-square and ANOVA tests were used for the intergroup comparisons. $\mathrm{P}<0.05$ values were considered statistically significant.

\section{RESULTS}

File records of 169 included in the study. The mean age at the time of admission was $27.3 \pm 26.1$ months, 96 patients $(56.8 \%)$ were boys, and $73(43.2 \%)$ patients were girls (Table 1). Birth weight was found as <2500 g in 59 (34.9\%) and 2500-4500 g in 110 (65.8\%) patients. Of all patients, $108(66.2 \%)$ were term and 55 (33.7\%) were preterm. When types of CP were evaluated; spastic type was found in 144 (86\%), dyskinetic type in $13(7.7 \%)$, mixed type in $6(3.6 \%)$. and ataxic-hypotonic type $5(3 \%)$ patients. The other demographic features are shown in Table 1.

When the risk factors were examined separately; the most common risk factor was asphyxia in 99 patients (58.9\%) followed by low birth weight in 59 patients (34.9\%), prematurity in 55 patients $(32.5 \%)$, and neonatal infections including meningitis in seven patients $(4.1 \%)$ and sepsis in six patients $(3.6 \%)$. As the other risk factors with relatively lower rates; hyperbilirubinemia was found in 16 patients $(9.5 \%)$, hydrocephalus in five patients $(3 \%)$, genetic anomalies in five patients $(3 \%)$, vascular processes such as intracranial hemorrhage and thrombosis in seven patients $(4.2 \%)$, and acute metabolic events such as hypoglycemia in one patient $(0.6 \%)$. No risk factor found in eight patients (4.7\%) (Table 2).

When imaging (computed tomography [CT] and magnetic resonance imaging [MRI]) findings of the patients were evaluated; encephalomalacia, which is accepted as the main finding of hypoxic ischemic encephalopathy (HIE), was found in 45 patients $(26.6 \%)$. Imaging evaluation was normal in 15 patients (8.9\%). It was found that imaging had not been performed in 21 patients (12.4\%) (Table 3 ).

When the cases are evaluated considering the possibility of epilepsy accompanying CP; epilepsy was observed in 60 patients (35.5\%). Regardless of the presence of epilepsy, EEG abnormality was found in 56 of 83 patients who had EEG (33.1\% of all patients) (Table 1). When the types of CP, gender, gestational age, birth weight, delivery mode and the presence of birth trauma were matched and compared; no statistically significant difference was found between type of CP and gender, low birth weight $(<2500 \mathrm{~g})$ and the presence of birth trauma $(p>0.05)$ (Table 4$)$.

\section{DISCUSSION}

$\mathrm{CP}$ is the most common physical disability in childhood, but it is very heterogeneous etiologically and clinically. Movement disorders associated with CP are categorized as spasticity, dyskinesia, ataxia or 


\section{Table 1: Patients' gender, mean age at admission, type of \\ cerebral palsy, birth weight, gestational ages, delivery mode, place of birth, risk factors, and electroencephalography ab- normality findings}

\section{Findings}

n

(\%)

Gender

Boy

Age of admission (month)

$<6$

6-12

$12-24$

$>24$

Type of CP

Spastic quadriparesis

Spastic diplegia

Spastic hemiparesis

Dyskinesia

Mixed

Ataxia-hypotonia

Spastic monoparesis

Birth weight $(\mathrm{g})$

$$
\begin{aligned}
& <2500 \\
& 2500-4500
\end{aligned}
$$$$
>4500
$$

Gestational age (week)

$$
\text { Term ( } \geq 38)
$$

Preterm ( $\leq 37)$

Delivery mode

$$
\text { Vaginal }
$$

Cesarean

Place of birth

$$
\text { Home }
$$

Hospital

Risk factor$$
1
$$$$
2
$$$$
\geq 3
$$

Epilepsy

No

Yes

Electroencephalography abnormality

\section{No}

86

Yes

56

56.8

43.2

14.8

12.4

29.6

43.2

38.5

25.6

20.7

7.7

3.6

3

1.2

34.9

65

0

66.2

33.7

56.8

40.4

10

90

54.4

29.5

11.2

8.7

35.5

50.9

CP: Cerebral palsy.

\section{Table 2: Risk factors of the patients in the study}

\section{Risk factors}

Asphyxia

Prematurity $(\leq 37)$

Low-birth weight $(<2500 \mathrm{~g})$

Hyperbilirubinemia

Neonatal meningitis

Neonatal sepsis

Thrombosis-intracranial hemorrhage

Genetic anomaly

Hydrocephalus

Hypoglycemia

Unknown

\section{n}

$\%$

58.9

32.5

34.9

9.5

4.1

3.6

4.2

3.0

3.0

0.6

4.7

\section{Table 3: Imaging findings of the patients}

\section{Imaging findings}

n

Encephalomalacia ( $\mathrm{H} \mathrm{E}$ )

45

Dysgeneses

Holoprosencephaly

Porencephalic cyst

Polymicrogyria

Schizencephaly

Corpus callosum anomaly

Choroid plexus cyst

Arnold chiari malformation

Basal ganglia hyperintensity

Cortical atrophy

Cerebral infarction

Hydrocephalus

Normal

Imaging not performed

mixed/other. Spasticity is the most common movement disorder seen in $80 \%$ of children with $\mathrm{CP}^{\left[{ }^{[2]}\right.}$

The incidence of CP differs between genders. CP is reported to me more common among boys. ${ }^{[4]}$ It is claimed that this tendency in male gender is based on a number of factors ranging from biological vulnerability and possible differences in brain organization to genetic disorders or the effect of female hormones to reduce the possible effects of brain damage. Therefore, gender is reported to have an effect in increasing the risk of developing CP. In studies investigating possible gender differences in specific forms of $\mathrm{CP}$, it is not exactly clear whether gender will also affect the severity of the motor impairment. ${ }^{[5]}$ In our study, the boy/girl ratio was $1.3 / 1$ and similar to the previous studies, the rate of males was higher. 
Table 4: Comparison of the types of cerebral palsy with gestational week, gender, birth weight, delivery mode, low-birth weight, and asphyxia in patients included in the study

\begin{tabular}{|c|c|c|c|c|c|}
\hline & Spastic quadriparesis & Spastic diplegia & Spastic hemiparesis & Other & $\mathbf{n}$ \\
\hline GW Mean $\pm S D$ & $37.01 \pm 4.6$ & $34.9 \pm 5.1$ & $38.4 \pm 3.8$ & $36.9 \pm 4.6$ & ns \\
\hline Boy/Girl (n) & $33 / 30$ & $24 / 19$ & $24 / 11$ & $14 / 10$ & ns \\
\hline Preterm $(\leq 37)(n)$ & 18 & 23 & 6 & 8 & \\
\hline Distribution & $1000-4000$ & $980-4000$ & $900-4500$ & $1200-4200$ & $\mathrm{p}<0.05$ \\
\hline Low-birth weight $(<2500 \mathrm{~g})(\mathrm{n})$ & 21 & 21 & 7 & 9 & ns \\
\hline Asphyxia (n) & 35 & 24 & 22 & 14 & ns \\
\hline
\end{tabular}

GW: Gestational week; C/S: Cesarean section; NSVD: Normal spontaneous vaginal delivery; ns: Not significant; SD: Standard deviation; Distribution: Median value $\left(25^{\text {th }}-7^{\text {th }}\right.$ percentiles).

Since early diagnosis will bring healing, timely diagnosis of $\mathrm{CP}$ cases is very important. Early physiotherapy has been reported to provide significant positive improvements in CP. In a study of 202 cases by Eriman et al., ${ }^{[6]}$ it has been reported that CP symptoms were noticed by the family in 102 cases, pediatrician in 97 cases, and environment in three cases. In our study, when the age of recognition of CP symptoms was questioned; it was found that CP symptoms were noticed in the neonatal period in 74 patients, between 0 and 6 months in 55 patients and after 1 year of age.

Although age at diagnosis of CP varies according to socioeconomic levels of countries, it has been generally reported between 12 and 24 months. ${ }^{[7]}$ It has been reported that establishing a diagnosis before 6 months of life is inadequate especially in mild or hypotonic cases. $^{[7,8]}$ The mean age at diagnosis was found as 8.98 months by Vurucu et al..$^{[9]}$ and 8.2 months by Bruck et al. ${ }^{[10]}$ Kabakuş et al. ${ }^{[11]}$ reported the mean age at admission as $23.4 \pm 3.8$ months and found that $42 \%$ of the cases were diagnosed before 1 year of age, $38 \%$ between 1 and 2 years and $20 \%$ after 2 year of age. The age of admission to our neurology outpatient clinic with the diagnosis of CP was under 6 months old in 25, between 6 and 12 months in 21, 12, and 24 months in 50 and $>24$ months of life in 73 and the mean age at admission was $27.3 \pm 26.1$. We think that early CP awareness is sufficient in our country, because in our study age at the time of admission was in infancy (<24 months) and patients who presented in the following months of age had been diagnosed in other centers.

$\mathrm{CP}$ has been reported to be more commonly developed in asphyxia cases than other risk factors. ${ }^{[12]}$ In our study, asphyxia was one of the most common causes of CP. When the frequency of asphyxia was evaluated according to the age of birth; it was found that asphyxia was 3 times more common in term cases. In our series, there was no patient with a birth weight $>4000 \mathrm{~g}$. Therefore, it was thought that it would be appropriate to investigate the reasons other than high birth weight when evaluating asphyxia in term infants.

In CP screening studies from abroad and countries known to be at different socio-economic levels, the incidence of asphyxia has been reported in a wide range between $3 \%$ and $50 \% .^{[12]}$ Whereas, in studies conducted in our country, this rate has been reported between $30 \%$ and $45 \% .{ }^{[13]}$ In our study, the rate of asphyxia was $58.9 \%$, remarkably higher than all reported. Among this; life and birth conditions and thus socio-economic level should be primarily discussed. In a series of 102 cases by Adın et al. ${ }^{[14]}$ from the Inonu University, the rate of asphyxia was reported as $51.9 \%$ in CP. This rate is the closest to our rate of asphyxia in the literature.

It has been reported that the majority of CP cases are delivered by normal vaginal method. In a study by Bringas-Grande et al. ${ }^{[15]} 68 \%$ of CP cases were reported to be delivered by normal vaginal method and 32 by C/S. In a study by Vurucu et al. ${ }^{[9]} 77.8 \%$ of the cases were delivered by normal vaginal method and $22.2 \%$ by $\mathrm{C} / \mathrm{S}$, while in another study by Kabakuş et al. $60 \%$ of the cases were delivered by normal vaginal method and $40 \%$ by C/S. ${ }^{[11]}$ In our study, $56.8 \%$ of the patients were delivered by normal vaginal method and $39.6 \% \mathrm{C} / \mathrm{S}$.

It has been reported in the literature that preterm births are the most important risk factor for the development of CP. ${ }^{[2]}$ It has been stated that as neonatal care units become more widespread, the number of infants kept alive has increased and gestational week has decreased, leading to an increase in the prevalence of $\mathrm{CP}$ in preterm births. ${ }^{[12]}$ It is known that prematurity and low-birth weight are the most common reasons in the countries where intensive care conditions are better and living chances are higher. Periventricular leukomalacia and intraventricular hemorrhage (IVH) are two main causes of CP development in premature infants. ${ }^{[16]}$ Furthermore, in our study, prematurity was among the important etiological factors.

Low-birth weight in CP seems to be an important reason for an effect that begins in the intrauterine period. However, when low birth weight is evaluated in the literature, some confusion of concepts as in the evaluation of the age of prematurity is remarkable. Some authors accepted $<2500 \mathrm{~g}$ as the low-birth weight criterion, ${ }^{[17]}$ while others determined the low-birth weight considering gestational age, ${ }^{[9]}$ and some authors mentioned the concept only as a low-birth weight and did not explain their criteria sufficiently. In our study, 59 patients were 
low birth weight infants and 55 were preterm. The difference between them reflected the small for gestational age.

Dyskinetic type CP is seen in late infancy and childhood due to bilirubin encephalopathy. ${ }^{[18]}$ Among the risk factors, hyperbilirubinemia was found in our 16 (9.5\%) patients. In studies reported from our country, hyperbilirubinemia has been reported as a cause of CP by $1-20 \% .^{[6,7,9,11]}$ Different rates were attributed to the level features of the centers where the studies were conducted.

In our study, we gathered vascular pathologies among CP risk factors in two subgroups as hemorrhagic and thrombotic, but under the same title. However, the result can be associated with vascular pathology in HIE. In this case, the potential of evaluating asphyxia together with thromboembolic and hemorrhagic factors increases. We concluded that a clear classification of vascular pathologies is difficult especially in units that are reference centers such as our outpatient clinic. Namely, it was unclear whether HIE might have occurred in the presence of hypoxia, thromboembolism, or hemorrhagic diathesis in the patients with leukomalacia findings verified with imaging, and especially in those with late admission. Therefore, in our study, patients with a definitive diagnosis of thromboembolic or hemorrhagic diathesis were gathered under vascular pathologies and the remaining encephalomalacia patients under the diagnosis of HIE. Looking at other studies, we found that clear classification of the cases was not possible and there was no explanation on this issue. In ethnic communities, where consanguineous marriages are common, the frequency of genetic etiology increases in CP. In a study conducted in Asia, CP was reported to be more common in ethnic societies where consanguineous marriages are common. ${ }^{[13]}$ According to the studies conducted in Turkey, the frequency of consanguineous marriage is between $21 \%$ and $33 \% .^{[8,19]}$ In a study from Turkey, among the prenatal causes consanguineous marriage was found as $24 \%$ and the most common etiologic factor in CP. ${ }^{[20]}$ In our study, consanguineous marriage was found in $38(22.5 \%)$ cases.

The most common type of $\mathrm{CP}$ is spastic type with the majority being spastic diplegic type. ${ }^{[21]}$ In our study, the most common type of CP was spastic $\mathrm{CP}$ with the most common subgroup being spastic quadriplegic $\mathrm{CP}$. Comparing birth weights and types of $\mathrm{CP}$, Gulati et al. reported that the incidence of spastic quadriplegia and spastic diplegia was statistically significant. ${ }^{[22]}$ In our study, when gestational weeks and birth weights were compared with the types of CP, these factors were found to be statistically significantly correlated with the development of spastic hemiparesis and spastic diplegia $(p<0.05)$. The most common types of CP are diplegia and tetraplegia in preterm infants. In fact, spastic diplegia and quadriplegia have been more commonly reported in the developed countries in parallel with the increasing rate of keeping premature infants at the lower gestational week alive. [8] Since asphyxia is a severe picture involving all motor pathways in terms of the location of involvement, while an even distribution is observed in spastic SP subtypes as in our study, spastic diplegia and quadriplegia CP types were more common, because periventricular area was more markedly involved in the preterm infants.

Magnetic resonance imaging (MRI) showed abnormalities in more than $80 \%$ of patients with CP. A MRI classification system (MRICS) was developed by the Surveillance of CP in Europe (SCPE). Here, the aim is interpretation and classification of brain MRI results in a simple way by both clinicians and other specialists caring CP patients. Due to the myelination development in the $1^{\text {st }}$ years of life, SCPE recommends classifying MRI images performed after the child reaches 2 years of age according to the MRICS system unless previous images show a specific pathology. ${ }^{[7,23,24]}$ Diffusion MRI should be preferred, because classical MRI is limited in identifying white matter pathways precisely. Similar to the literature, in our study, CT and MRI showed various abnormalities that can be grouped as cerebral atrophy, encephalomalacia, cerebral infarction, intracranial hemorrhage, hydrocephalus, cortical-subcortical dysgenesis, and intensity changes (Table 3).

Epilepsy may also occur in the follow-up of children with CP. In our study, EEG abnormality was found in 56 of our CP patients whose EEG examination was performed due to presumed epilepsy. In a screening study by İpek et al. ${ }^{[7]}$ on $\mathrm{CP}$, epilepsy was found by $35.8 \%$; with EEG abnormality was found in $31.2 \%$ of these patients. In line with the other studies, in our study, EEG abnormality was found in 56 of 169 patients (33.1\%).

\section{CONCLUSION}

Retrospective cross-sectional design of the study was the main limitation. In conclusion, results of our study indicate that asphyxia is one of the main causes of CP development in our country. CP screening studies, which are accepted as an indicator of the socio-economic and cultural structure, require standardization. Considering central nervous system maturation, brain plasticity and changing clinical picture, the definitive diagnosis of CP cannot be made before 1 year of age. However, occasionally symptoms showing possibility of $\mathrm{CP}$ may be seen in early infancy. Although there are studies investigating diagnostic tools that enable early diagnosis in premature infants with abnormalities in neuroimaging, determining the exact age at which $\mathrm{CP}$ should be diagnosed is still a subject open to research.

\section{Statement}

Ethics Committee Approval: The Cerrahpaşa University Faculty of Medicine Clinical Research Ethics Committee granted approval for this study (date: 24.11.2009, number: D-008).

Informed Consent: Written informed consent was obtained from patients who participated in this study.

Peer-review: Externally peer-reviewed.

Author Contributions: Concept - SPK; Design - HHT; Supervision - HHT; Resource - HHT; Materials - SPK; Data Collection and/or Processing - HHT; Analysis and/or Interpretation - HHT; Literature Search - HHT; Writing - HHT; Critical Reviews - HHT.

Conflict of Interest: The authors have no conflict of interest to declare.

Financial Disclosure: The authors declared that this study has received no financial support.

\section{REFERENCES}

1. Hallman-Cooper JL, Gossman W. Cerebral Palsy. Treasure Island, FL: StatPearls; 2020.

2. Sadowska M, Sarecka-Hujar B, Kopyta I. Cerebral palsy: Current opinions on definition, epidemiology, risk factors, classification and treatment options. Neuropsychiatr Dis Treat 2020;16:1505-18.

3. Yalçın S, Özaras N, Dormans JP, Sussman M. Cerebral Palsy 
Orthopaedic Treatment and Rehabilitation. İstanbul, Turkey: Mas Matbaacılık; 2000.

4. Direk M, Sarıgeçili E, Akça M, Kömür M, Okuyaz C. Serebral palsili çocuklarda sosyodemografik veriler ve yürüme potansiyeli üzerine etki eden faktörlerin değerlendirilmesi. Mersin Üniv Saglık Bilim Derg 2019;12(2):248-56.

5. Romeo DM, Sini F, Brogna C, Albamonte E, Ricci D, Mercuri E. Sex differences in cerebral palsy on neuromotor outcome: A critical review. Dev Med Child Neurol 2016;58(8):809-13.

6. Eriman EÖ, İçağasıoğlu A, Demirhan E, Kolukısa Ş, Aras H, Haliloğlu S, et al. Serebral palsili 202 olgunun demografik verileri ve klinik özellikler. Türk Fiz Tıp Rehab Derg 2009;55:94-7.

7. İpek B, Ecevit Ç, İpek I, Kocabaş Ö, Kavaklı T, Öztürk A. The evaluation of 371 cases with cerebral palsy between January 1984 and December 2004. J Neurol Sci 2007;24:270-9.

8. Sankar C, Mundkur N. Cerebral palsy definition, classification, etiology and early diagnosis. Indian J Pediatr 2005;72(10):865-8.

9. Vurucu S, Sarı O, Gülgün M, Ünay B, Akın R, Özcan O. Serebral palsili hastalarimizin etiyolojik, klinik ve laboratuvar bulgularinin değerlendirilmesi. TAF Prev Med Bull 2008;7(6):477-84.

10. Bruck I, Antoniuk S, Spessatto A, De Bem RS, Hausberger R, Pacheco CG. Epilepsy in children with cerebral palsy. Arq Neuropsiquiatr 2001;59(1):35-9.

11. Kabakuş N, Açık Y, Kurt A, Özdiller DŞ, Kurt AN, Aygün AD. Serebral palsili hastalarımızın demografik, etiyolojik ve klinik özellikleri. Çocuk Sağlığı Hastalıkları Derg 2005;48:125-9.

12. Michael-Asalu A, Taylor G, Campbell H, Lelea LL, Kirby RS. Cerebral palsy diagnosis, epidemiology, genetics, and clinical update. Adv Pediatr 2019;66:189-208.

13. Sucuoğlu H. Serebral palsili hastalarin demografik ve klinik özellikleri. İstanbul Med J 2018;19(3):219-24.

14. Adın S, Aslan M, Doğan M, Yakıncı C, Alkan A. Term ve preterm serebral palsili çocuklarda etiyoloji, klinik ve manyetik rezonans görüntüleme Bulgulari. İnönü Üniv Tıp Fakült Derg 2009;6(3):169-72.

15. Bringas-Grande A, Fernandez-Luque A, Garcia-Alfora C, Barrera-Chacon M, Toledo-Gonzalez M, Dominguez-Rolda JM. Cerebral palsy in childhood: 250 cases report. Rev Neurol 2002;35(9):812-7.

16. Platt MJ, Pateliadis CP, Häusler M. Aetiological factors. In: Pateliadis CP, editors. Cerebral Palsy: A Multidisciplinary Approach. $3^{\text {rd }}$ ed. Cham, Switzerland: Springer International Publishing; 2018. p. 49-58.

17. Surmana G, Hemming K, Platt MJ, Parkes J, Green A, Hutton J, et al. Children with cerebral palsy: Severity and trends over time. Paediatr Perinatal Epidemiol 2009;23(6):513-21.

18. Karımzadeh $P$, Fallahı $M$, Kazemıan M, Taleghani NT, Nouripour S, Radfar M. Bilirubin induced encephalopathy. Iran J Child Neurol 2020;14(1):7-19.

19. Serdaroğlu A, Cansu A, Ozkan S, Tezcan S. Prevalance of cerebral palsy in Turkish children between the ages of 2 and 16 years. Dev Med Child Neurol 2006;48(6):413-6.

20. Aydın G, Caner K, Demir SÖ, Keleş I, Demir M, Orkun S. Serebral palsili 314 olgunun etiyolojik demografik ve klinik özellikleri ve bu özelliklerin rehabilitasyon sonuçlarına etkisi. Fiziksel Tıp 2005;8:33-40.

21. Almasri NA, Saleh M, Abu-Dahab S, Malkawi SH, Nordmark E. Development of a cerebral palsy follow-up registry in Jordan (CPUPJordan). Child Care Health Dev 2017;44(1):131-9.

22. Gulati S, Sondhi V. Cerebral palsy: An overview. Indian J Pediatr 2018;85(11):1006-16.

23. Himmelmann K, Horber V, De La Cruz J, Horridge K, Mejaski-Bosnjak $\mathrm{V}$, Hollody $\mathrm{K}$, et al. MRI classification system (MRICS) for children with cerebral palsy: Development, reliability, and recommendations. Dev Med Child Neurol 2017;59(1):57-64.

24. Kwong KL, Wong YC, Fong CM, Wong SN, So KT. Magnetic resonance imaging in 122 children with spastic cerebral palsy. Pediatr Neurol 2004;31(3):172-6. 